\title{
PEDIATRIC ASTHMA: IMPACT OF THE DISEASE IN CHILDREN RECEIVING OUTPATIENT TREATMENT IN SOUTHERN BRAZIL
} Asma pediátrica: impacto da doença em crianças

\author{
Cristian Roncada, ${ }^{a}$ (D), Rodrigo Godinho de Souza ${ }^{a}$ (D), \\ Daniela Duarte Costa ${ }^{a}$ (1) Paulo Márcio Pitrez ${ }^{a}$
}

\section{ABSTRACT}

Objective: To evaluate the impact of pediatric asthma on patients of a specialized outpatient clinic in Southern Brazil.

Methods: The study included children aged 8 to 17 years old with asthma diagnosis (mild, moderate and severe) under treatment at the asthma clinic of Hospital São Lucas da Pontifícia Universidade Católica do Rio Grande do Sul (PUCRS), Brazil. Measurements of spirometry, quality of life, disease control and atopy tests were applied.

Results: A total of 66 children were included in the study and divided into groups, according to the severity of the disease: mild, moderate or severe asthma. The results showed similarities in both the treatment and the impact of asthma between groups, except for adherence to treatment: the group with mild asthma showed least adherence to treatment, and the group with severe asthma, greater adherence $(p=0.011)$. As to school absenteeism, the group with severe asthma showed higher frequency $(p=0.012)$, with over 10 days per year $(p=0.043)$. Spirometry showed lower volume/capacity for the group with moderate asthma, followed by the groups with severe and mild asthma. All groups had a high prevalence of allergic asthma, with mites as the main allergens. For quality of life (QOL), and health-related quality of life (HRQOL) levels, there were no differences between groups. In addition, the values were close to the acceptable levels for the total score and for each one of the six domains. The same occurred for the HRQOL-asthma module.

Conclusions: QOL and HRQOL present acceptable levels regardless of the severity of the disease.

Keywords: Quality of life; Asthma; Management; Children; Adolescents.

\section{RESUMO}

Objetivo: Avaliar o impacto da asma pediátrica de pacientes em acompanhamento ambulatorial em um centro de referência em pneumopediatria do Sul do Brasil.

Métodos: Participaram do estudo crianças com idade entre oito e 17 anos, com diagnóstico de asma (leve, moderada e grave), em acompanhamento no ambulatório de asma do Hospital São Lucas da Pontifícia Universidade Católica do Rio Grande do Sul (PUCRS). Foram verificadas medidas de espirometria, avaliação dos níveis de qualidade de vida, controle da doença e teste de atopia.

Resultados: Sessenta e seis crianças participaram do estudo, divididas em três grupos (asma leve, moderada e grave). Evidenciaram-se semelhanças tanto no tratamento quanto no impacto da asma, exceto para a adesão ao tratamento $(p=0,011)$, em que o grupo de asma leve é o que menos adere e o grupo de asma grave o que mais adere ao tratamento. Em relação ao absenteísmo escolar, o grupo de asma grave apresentou o maior valor $(p=0,012)$, com mais de dez dias/ano $(p=0,043)$. As espirometrias demonstram menor volume/capacidade para o grupo de asma moderada, seguido do grupo de asma grave e asma leve. Os grupos possuem alta prevalência de asma alérgica, tendo os ácaros como os principais alérgenos. Quanto à qualidade de vida (QV) e à qualidade de vida relacionada à saúde (QVRS), não houve diferença entre os grupos. Além disso, os valores apresentados estão próximos aos níveis aceitáveis, tanto para o escore total quanto para os seis domínios analisados. O mesmo ocorre para o módulo QVRS-asma.

Conclusões: Os níveis de QV e de QVRS demonstram-se aceitáveis, independentemente da gravidade da doença.

Palavras-chave: Qualidade de vida; Asma; Manejo; Crianças; Adolescentes. 


\section{INTRODUCTION}

Asthma is one of the most frequent chronic diseases in the pediatric population worldwide, considered a low-lethality disease, but with high rates of morbidity, which makes it a serious public health problem. Its affections are high to the point of being one of the main diseases in terms of emergency visits in emergency care units and hospital admissions. ${ }^{1}$ Its prevalence has been steadily increasing in the pediatric population, and despite advances in the management and treatment of the disease, high rates of morbidity and mortality are alarming. ${ }^{1,2}$

This respiratory disease is the result of three specific characteristics: airway obstruction, inflammation and bronchial hyperresponsiveness. Such characteristics cause three clinical manifestations: dry cough, dyspnea and wheezing. Knowing this, as well as its manifestations, the World Health Organization (WHO) developed a series of guidelines involving the treatment, self-management and control of asthma. ${ }^{1}$ During crises, the patient must be treated immediately with bronchodilator, enabling increased airflow. ${ }^{2}$ Self-management of asthma involves education and patient awareness of the importance of treatment and self-control when in crisis. Asthma control occurs with the practice of exercises, which strengthen the muscles involved in breathing, and adherence to the treatment prescribed by the pediatrician. ${ }^{1}$

Management for the treatment of children and adolescents with asthma is based on anamnesis, clinical examination and, whenever possible, pulmonary function tests (spirometry) and assessment of allergies. ${ }^{2}$ An important factor in the classification of disease severity is the assessment of quality of life (QOL), which is an individual perception, of multiple factors that directly or indirectly affect life, for example, physical, cultural, social, environmental and emotional aspects. ${ }^{3}$ When QOL is affected due to a specific disease, this is called health-related quality of life (HRQOL), ${ }^{3}$ which is measured with the aid of specific questionnaires, such as the Kinder Lebensqualität Fragebogen (KINDL-R) ${ }^{4}$ the Pediatric Asthma Quality of Life Questionnaire (PAQLQ) ${ }^{5}$, and the Pediatric Quality of Life Inventory TM (PedsQL TM). ${ }^{6}$ Another important factor is disease control, which, likewise, is assessed using specific questionnaires; the most used ones are the Asthma Control Test (ACT, ${ }^{7}$ the Asthma Control Questionnaire (ACQ) ${ }^{8}$, and the Global Initiative for Asthma (GINA). ${ }^{1}$ With the application of all the methods described, diagnosis, treatment, self-management, control, physical activity and periodic evaluation, the QOL of patients becomes much better and easier to maintain at acceptable levels. Based on these facts, the objective of the study was to evaluate the impact of pediatric asthma in patients undergoing outpatient follow-up at a referral center for pneumopediatrics in Southern Brazil.

\section{METHOD}

From March to December 2014, a cross-sectional study was carried out in children with a clinical diagnosis of persistent asthma (mild, moderate and severe), based on the GINA guidelines, ${ }^{1}$ undergoing outpatient follow-up at a pediatric asthma reference center in Porto Alegre, Rio Grande do Sul. The sample was selected by convenience criterion, with the participation of children aged between eight and 17 years old in follow-up for at least six months, with no history of physical or cognitive disabilities that could compromise the assessments of outcome.

At the time of inclusion in the study, a clinical questionnaire was applied, containing questions with the characterization of the sample, the history of crises and treatments for the disease. In addition, pulmonary function parameters/ indexes - spirometry were assessed: forced expiratory volume in one second $\left(\mathrm{FEV}_{1}\right)$, forced vital capacity $(\mathrm{FVC})$, ratio of $\mathrm{FEV}_{1}$ and $\mathrm{FVC}\left(\mathrm{FEV}_{1} / \mathrm{FVC}\right)$ and forced expiratory flow between the 25 and $75 \%$ percentiles (FEF25-75\%), presented by $\mathrm{Z}$ score-both basal and after the use of bronchodilator ( $400 \mu \mathrm{g}$ of salbutamol);9 of QOL, with the KINDL-R questionnaire, ${ }^{10}$ composed of 24 generic items about physical and emotional well-being, self-esteem, family, friends and school and 15 items related to health (asthma). Disease control was also assessed with the ACT, ${ }^{11}$ with acceptable levels with scores equal to or greater than 20 points, adherence to treatment and perception of changes in health (containing a question for each item), body mass index-BMI (weight/height ${ }^{2}$ ), presented by $\mathrm{Z}$ score, ${ }^{12}$ and physical activities, ${ }^{13}$ consisting of items about the practice of physical activity and the time spent on them in the last seven days, as well as items related to the time spent in front of screens (television, video game and computer).

For the purpose of assessing atopy, the skin prick test was applied, ${ }^{14}$ with immediate reading on patients' forearms, containing eight types of antigen for evaluation in asthma (Dermatophagoides pteronyssinus, Dermatophagoides farinae, Blomia tropicalis, grasses, cockroach, air fungi, dog epithelium and cat epithelium), in addition to positive (histamine) and negative (serum) testing. Initially, tests were considered valid by presenting a papule $\geq 3 \mathrm{~mm}$ for histamine (positive test) and not presenting a papule for serum (negative test) after 15 minutes of application. After this check, patients with a papule $\geq 3 \mathrm{~mm}$ were considered positive (atopic) for any of the eight antigens tested. All tests applied in the present study were carried out by a team previously trained and qualified for such measures and assessments, with questionnaires administered in the form of interviews and objective tests, according to the rules stipulated by the collection instruments previously mentioned.

For the purposes of statistical analysis, categorical values are expressed by absolute and relative numbers (N\%), and 
continuous values by means and standard deviations. For comparison between groups, chi-square tests and analysis of variance (ANOVA) are used, according to the analyzed variable. In addition, for the configuration of the study and comparison between groups, the minimum acceptable sample size was 19 subjects per group (mild, moderate and severe), with an effect size (p) of 0.3 point, confidence level $(\beta)$ minimum of $80 \%$ and sampling error $(\alpha)$ of up to $5 \%$.

The study was approved by the Research Ethics Committee (CEP) of Pontifícia Universidade Católica do Rio Grande do Sul (PUCRS), under substantiated opinion No. 1.535/2011. Both patients and guardians consented to participate in the study by the consent term (children/adolescents) or the free and informed consent (guardians).

\section{RESULTS}

The sample of this study was composed of 66 children with an average age of $10.5 \pm 2.1$ years, $40(61 \%)$ of whom were male; $43(65 \%)$ belonging to the economic and social class C; 51 (77\%) of Caucasian ethnicity and severity of mild, moderate and severe asthma (32, 36 and 32\%, respectively); 33 (50\%) with BMI above normal; 30 (45\%) with acceptable levels of asthma control; 32 (48\%) with acceptable levels of physical activity (active); and $53(80 \%)$ with high rates of physical inactivity, with time in front of screens (TIFS) - televisions, video games or computers $-\geq 2$ hours/day. In addition, mothers are the main caregivers (companions) in medical consultations $(51 ; 77 \%)$. Table 1 shows sample characterization values by asthma groups (mild $-\mathrm{n}=21$, moderate $-\mathrm{n}=24$, and severe $-\mathrm{n}=21$ ).

Table 2 shows the categorical values, as well as the comparisons between the three asthma groups, demonstrating that there are similarities in both treatment and asthma impact, with significant differences only for adherence to treatment $(\mathrm{p}=0.011)$ : the group with mild asthma is the least adherent to the treatment, and the group with severe asthma is the one that adheres the most. In addition to this outcome, differences were found for school absenteeism: the group with severe asthma was the one with the highest scores $(\mathrm{p}=0.012)$, with the longest periods of absence from school (more than ten days/year; $\mathrm{p}=0.043$ ).

Table 3 shows the continuous values ( $\mathrm{Z}$ score) for representing pulmonary function (spirometry), comparing the

Table 1 Characterization of the groups with asthma (mild, moderate and severe).

\begin{tabular}{|c|c|c|c|c|c|c|c|}
\hline \multirow{2}{*}{ Categorical variables } & \multicolumn{2}{|c|}{ Mild } & \multicolumn{2}{|c|}{ Moderate } & \multicolumn{2}{|c|}{ Severe } & \multirow{2}{*}{ p-value } \\
\hline & $\mathrm{n}=21$ & $\%$ & $n=24$ & $\%$ & $\mathrm{n}=21$ & $\%$ & \\
\hline Accompanying person (mother) & 15 & 71.4 & 20 & 83.3 & 16 & 76.2 & 0.560 \\
\hline Economic and social class (class C) & 15 & 71.4 & 14 & 58.3 & 14 & 66.7 & 0.649 \\
\hline Gender (male) & 17 & 80.9 & 14 & 58.3 & 9 & 42.9 & 0.061 \\
\hline Ethnicity (caucasian) & 18 & 85.7 & 19 & 79.2 & 14 & 66.7 & 0.404 \\
\hline \multicolumn{8}{|l|}{ BMI (Z score) } \\
\hline Eutrophic & 9 & 42.9 & 12 & 50.0 & 12 & 57.1 & \multirow{3}{*}{0.676} \\
\hline Overweight & 5 & 23.8 & 6 & 25.0 & 4 & 19.0 & \\
\hline Obesity & 7 & 33.3 & 6 & 25.0 & 5 & 23.8 & \\
\hline Physical activity level (active) & 10 & 47.6 & 13 & 54.2 & 9 & 42.9 & 0.751 \\
\hline Physical inactivity level ( $\geq 2$ hours/day)* & 18 & 85.7 & 20 & 83.3 & 15 & 71.4 & 0.461 \\
\hline Asthma control test (controlled) & 10 & 47.6 & 11 & 45.8 & 9 & 42.9 & 0.953 \\
\hline Continuous variables & AV & $\pm \mathrm{SD}$ & AV & \pm SD & AV & \pm SD & p-value \\
\hline Age & 11.0 & \pm 2.6 & 10.8 & \pm 2.3 & 9.7 & \pm 1.6 & 0.106 \\
\hline First asthma attack (in months) & 28.7 & \pm 7.6 & 34.0 & \pm 9.0 & 20.4 & \pm 5.3 & 0.362 \\
\hline Outpatient care (in months) & 39.5 & \pm 9.6 & 55.4 & \pm 5.5 & 35.3 & \pm 4.9 & 0.294 \\
\hline Asthma control test (ACT) & 18.9 & \pm 3.5 & 18.3 & \pm 4.0 & 18.0 & \pm 4.0 & 0.740 \\
\hline Physical activity time (in minutes) & 320.0 & \pm 41.3 & 224.2 & \pm 22.3 & 196.9 & \pm 22.7 & 0.413 \\
\hline Physical downtime (in hours) & 3.6 & \pm 2.1 & 3.9 & \pm 2.8 & 2.9 & \pm 1.7 & 0.332 \\
\hline
\end{tabular}

n: number of participants; \%: percentage of participants; BMI: body mass index; AV: average; SD: standard deviation; *tendency to physical inactivity for staying in front of screens (televisions, computers or video games) for more than 2 hours/day. 
three groups of asthma, showing a difference between basal values $\left(\mathrm{FEV}_{1}, \mathrm{FVC}\right.$ and FEF25-75\% - p $=0.002, \mathrm{p}=0.001$ and $\mathrm{p}=0.036$, respectively) and post-use of bronchodilator $\left(\mathrm{FEV}_{1}\right.$ and $\mathrm{FVC}-\mathrm{p}=0.008$ and $\mathrm{p}=0.037$, respectively). The values show lower volume/capacity for the group with moderate asthma, followed by the group with severe asthma and the group with mild asthma. In addition, when comparing the difference between pre- and post-bronchodilator, no statistical differences were found.
Figure 1 represents the prevalence levels of atopy, with no differences between the groups, but, at the same time, demonstrating that they have a high prevalence of allergic asthma, with mites being the main factors of atopy and domestic animals (dogs and cats) those with the lowest prevalence rates.

Figure 2 represents QOL levels (generic), as well as HRQOLasthma levels, with no differences between groups. In addition, the values presented are close to acceptable levels ( $\geq 70$ points) both for the total score and for the six domains composed of

Table 2 Comparison between treatment and asthma impact among asthma groups (mild, moderate and severe).

\begin{tabular}{|c|c|c|c|c|c|c|c|}
\hline & \multicolumn{2}{|c|}{ Mild } & \multicolumn{2}{|c|}{ Moderate } & \multicolumn{2}{|c|}{ Severe } & \multirow{2}{*}{ p-value } \\
\hline & $\mathrm{n}=\mathbf{2 1}$ & $\%$ & $n=24$ & $\%$ & $\mathrm{n}=21$ & $\%$ & \\
\hline \multicolumn{8}{|l|}{ Asthma treatment } \\
\hline Crisis prescription & 17 & 80.95 & 18 & 75.00 & 13 & 65.00 & 0.508 \\
\hline Continuous treatment for asthma & 14 & 66.67 & 19 & 79.17 & 19 & 90.48 & 0.173 \\
\hline \multicolumn{8}{|l|}{ Forget to administer treatment } \\
\hline Never & 0 & 0.00 & 3 & 15.79 & 9 & 47.37 & \multirow{3}{*}{$0.011^{*}$} \\
\hline Sometimes & 14 & 100.00 & 15 & 78.95 & 10 & 52.63 & \\
\hline Ever & 0 & 0.00 & 1 & 5.26 & 0 & 0.00 & \\
\hline \multicolumn{8}{|l|}{ Change in health after treatment } \\
\hline Better & 10 & 71.43 & 14 & 73.68 & 13 & 68.42 & \multirow{3}{*}{0.374} \\
\hline Equal & 2 & 14.29 & 3 & 15.79 & 3 & 15.79 & \\
\hline Worse & 2 & 14.29 & 2 & 10.53 & 3 & 15.79 & \\
\hline \multicolumn{8}{|l|}{ Impact of asthma over the last 12 months } \\
\hline Dry cough at night & 14 & 66.67 & 19 & 79.17 & 19 & 90.48 & 0.143 \\
\hline Sleep disturbed by asthma & 14 & 66.67 & 16 & 66.67 & 18 & 85.71 & 0.965 \\
\hline Exercise-induced asthma & 14 & 66.67 & 15 & 62.50 & 15 & 71.43 & 0.820 \\
\hline Asthma attacks & 20 & 95.24 & 21 & 87.50 & 19 & 90.48 & 0.652 \\
\hline 1 to 3 times & 13 & 61.90 & 10 & 41.67 & 4 & 19.05 & \multirow{4}{*}{0.169} \\
\hline 4 to 7 times & 2 & 9.52 & 1 & 4.17 & 4 & 19.05 & \\
\hline 8 to 11 times & 1 & 4.76 & 4 & 16.67 & 3 & 14.29 & \\
\hline At least one crisis a month & 4 & 19.05 & 6 & 25.00 & 8 & 38.10 & \\
\hline Medical consultation for asthma crisis & 20 & 95.24 & 21 & 87.50 & 19 & 90.48 & 0.652 \\
\hline Did not consult (treated at home) & 17 & 85.00 & 14 & 66.67 & 10 & 52.63 & \multirow{3}{*}{0.082} \\
\hline In primary care & 3 & 15.00 & 5 & 23.81 & 7 & 36.84 & \\
\hline In tertiary care & 0 & 0.00 & 2 & 9.52 & 2 & 10.53 & \\
\hline Hospitalization & 0 & 0.00 & 1 & 7.14 & 2 & 13.33 & 0.379 \\
\hline School absenteeism & 10 & 47.62 & 16 & 66.67 & 19 & 90.48 & $0.012^{*}$ \\
\hline 1 to 5 days & 6 & 60.00 & 5 & 31.25 & 4 & 21.05 & \multirow{3}{*}{$0.043^{*}$} \\
\hline 6 to 10 days & 2 & 20.00 & 6 & 37.50 & 5 & 26.32 & \\
\hline More than 10 days & 2 & 20.00 & 5 & 31.25 & 10 & 52.63 & \\
\hline
\end{tabular}

n: number of participants; \%: percentage of participants; *significance value with $p<0.05$, chi-square test being applied. 
Table 3 Comparison of lung function (spirometry) among asthma groups (mild, moderate and severe).

\begin{tabular}{|c|c|c|c|c|c|c|c|}
\hline & \multicolumn{2}{|c|}{ Mild } & \multicolumn{2}{|c|}{ Moderate } & \multicolumn{2}{|c|}{ Severe } & \multirow{2}{*}{ p-value } \\
\hline & AV & \pm SD & AV & \pm SD & AV & $\pm \mathrm{SD}$ & \\
\hline \multicolumn{8}{|c|}{ Pre-bronchodilator (Z score) } \\
\hline $\mathrm{FEV}_{1}$ & 0.89 & \pm 1.32 & -0.67 & \pm 1.48 & 0.61 & \pm 1.77 & $0.002^{*}$ \\
\hline FVC & 1.49 & \pm 1.25 & -0.18 & \pm 1.46 & 0.85 & $1 \pm .66$ & $0.001^{*}$ \\
\hline $\mathrm{FEV}_{1} / \mathrm{FVC}$ & -0.79 & \pm 1.04 & -0.77 & \pm 1.25 & -0.42 & \pm 1.29 & 0.522 \\
\hline $\mathrm{FEF}_{25-75 \%}$ & -0.30 & \pm 1.17 & -1.00 & \pm 1.28 & 0.10 & \pm 1.76 & $0.036^{*}$ \\
\hline \multicolumn{8}{|c|}{ Post-bronchodilator (Z score) } \\
\hline $\mathrm{FEV}_{1}$ & 1.69 & \pm 1.48 & 0.24 & \pm 1.63 & 1.28 & \pm 1.60 & $0.008^{*}$ \\
\hline FVC & 1.81 & \pm 1.60 & 0.41 & \pm 2.12 & 1.21 & \pm 1.51 & $0.037^{*}$ \\
\hline $\mathrm{FEV}_{1} / \mathrm{FVC}$ & -0.21 & \pm 0.67 & -0.14 & \pm 1.14 & 0.00 & \pm 1.07 & 0.778 \\
\hline $\mathrm{FEF}_{2575 \%}$ & 0.53 & \pm 0.92 & 0.13 & \pm 1.64 & 0.71 & \pm 1.52 & 0.371 \\
\hline \multicolumn{8}{|c|}{ Pre/post-bronchodilator difference (\%) } \\
\hline $\mathrm{FEV}_{1}$ & 8.27 & \pm 8.86 & 10.51 & \pm 9.73 & 7.60 & \pm 7.96 & 0.519 \\
\hline FVC & 3.19 & \pm 5.19 & 6.31 & \pm 9.80 & 4.37 & \pm 5.69 & 0.359 \\
\hline $\mathrm{FEV}_{1} / \mathrm{FVC}$ & 13.51 & \pm 22.45 & 15.02 & \pm 26.08 & 10.00 & \pm 23.03 & 0.777 \\
\hline $\mathrm{FEF}_{25-75 \%}$ & 23.32 & \pm 23.66 & 22.34 & \pm 23.88 & 13.18 & \pm 18.46 & 0.267 \\
\hline
\end{tabular}

AV: average; SD: standard deviation; *significance value with $p<0.05$, independent Student t-test being applied; FEV : forced expiratory volume in one second; FVC: forced vital capacity; FEV,/FVC: ratio between forced expiratory volume in one second and forced vital capacity (Tiffenau); $\mathrm{FEF}_{25-75 \%}$ : forced expiratory flow in the 25 and $75 \%$ percentiles.

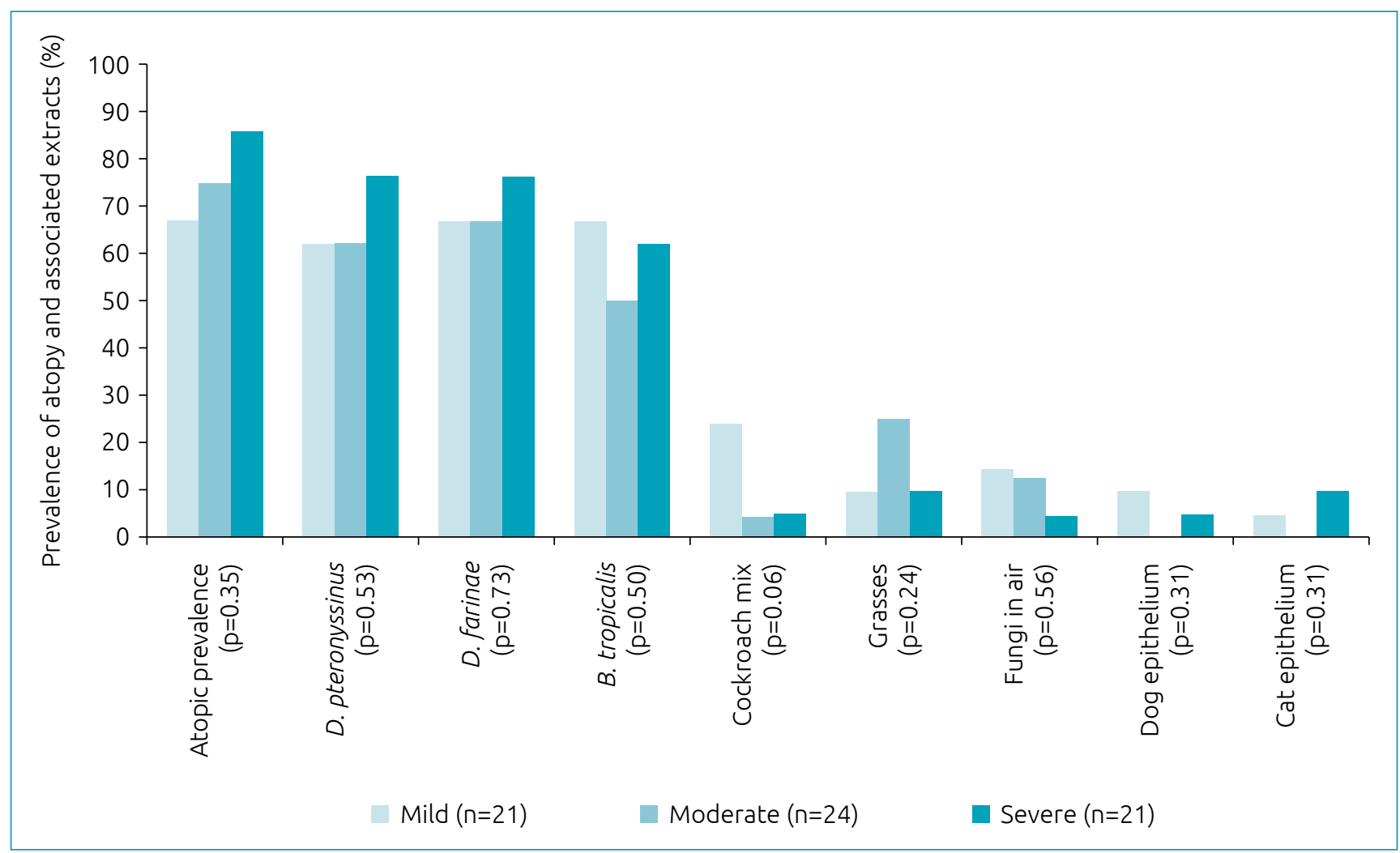

Figure 1 Assessment of atopic prevalence by asthma severity groups. 
the generic questionnaire. As for the HRQOL-asthma module, in which the acceptable values are inversely proportional, the values were also close to the acceptable levels ( $\leq 30$ points).

\section{DISCUSSION}

The results show that the impact of pediatric asthma is high, regardless of the severity of the disease, compromising aspects of daily life due to low adherence to treatment, making it difficult to control, increasing levels of disease recurrence (daytime, nighttime and exercise-induced symptoms), emergency visits and hospitalizations. The results also point to an increase in school absenteeism, BMI, physical inactivity and atopy. In addition, there are differences in lung function, especially for patients with moderate asthma (decreased capacity/volume). However, the QOL and HRQOL-asthma levels are acceptable, regardless of the severity of the disease.

In assessing BMI, the results demonstrate that children with a clinical diagnosis of asthma have high rates of overweight and obesity, regardless of the severity of the disease. In a study with 324 urban asthmatic children, Holderness et al. ${ }^{15}$ reported that patients have an overweight rate of $15 \%$ and an obesity rate of $31 \%$, identifying that children with limited physical activity have a significantly higher chance of being overweight or obese-2.1 Odds Ratio (OR), 95\% confidence interval (95\% CI) 2 3.8. In addition, children with symptoms of poorly controlled asthma, compared to children with milder symptoms, report having limitations to perform physical activities ( 58 versus $43 \%, \mathrm{p}=0.01$ ). The authors conclude that urban children with persistent asthma have high rates of overweight and obesity, which generates limitations to physical activities, resulting in uncontrolled disease in $47 \%$ of cases. In another study, Chen et al. ${ }^{16}$ warn of the risk of increased adiposity in the short term, which may increase the incidence or recurrence of symptoms of childhood asthma, besides increased airway inflammation.

In the present study, it was demonstrated that $48 \%$ of the evaluated children have acceptable levels of physical activity (active), and the others (52\%), high levels of physical inactivity, with the aggravating fact that $80 \%$ of these have high scores for TIFS ( $\geq 2$ hours daily). Studies ${ }^{17-19}$ point out that the levels of physical inactivity have been gradually increasing in children and adolescents, simultaneously, which corroborates the importance of evaluating possible risks associated with physical inactivity, such as irregular eating habits or TIFS $\geq 2$ hours daily. Lochte et al., ${ }^{20}$ in their meta-analysis, assessed the relation



Figure 2 Assessment of quality of life by asthma severity groups. 
between asthma symptoms and physical inactivity, pointing out evidence that children and adolescents with low levels of physical activity are at increased risk for the appearance of new asthma symptoms (disease recurrence).

Furthermore, Hoare et al., ${ }^{18}$ in a systematic review, assessed the association between sedentary behavior and mental health problems in children and adolescents, pointing out strong evidence for the positive relation between depressive symptoms and TIFS, especially for children and adolescents with a mean TIFS between two and three hours daily. Moderate evidence was also found for the relation between self-esteem and sedentary behavior, indicating lower levels of self-esteem among those who reported higher levels of TIFS (watching TV and using the computer). Both studies indicate that such findings serve as an alert for the importance of assessing the negative impact on pediatric health related to lifestyle changes, attributed to the new behavioral, environmental and social trends of this population.

Regarding the assessment of asthma control indexes, the results of the present study demonstrate that $55 \%$ of the assessed population does not have acceptable total score scores for disease control - ACT questionnaire score $\geq 20$ points - regardless of the severity of the disease. Halwani et al. ${ }^{21}$ evaluated 297 children and pointed out that most patients (60.3\%) had uncontrolled symptoms, of which intermittent asthmatics had better scores on the total ACT score compared to patients with more severe symptoms, which was attributed to the lack of adherence to treatment or the inappropriate use of inhalation devices. In another study, Saito et al. ${ }^{22}$ evaluated 229 asthmatic patients and reported that the management for asthma control must take into account the biological, psychological and treatment adherence problems, thus leading to a more proactive and aimed at better disease control.

As to the treatment for asthma, as well as its adherence, the present study shows that $74 \%$ of asthmatics have a crisis prescription for preventive treatment, and $79 \%$ use continuous medication, regardless of the severity of the disease. About half of patients with severe asthma, 15\% of patients with moderate asthma and no patient with mild asthma report never forgetting to administer the medication. Similar findings were noted in a Dutch cohort, ${ }^{23}$ in which children with a history of high treatment adherence had higher rates of exacerbations during follow-up compared to children with lower treatment adherence rates. In conclusion, the study points out that the characteristics of children with good adherence are compatible with more severe asthma, suggesting that adherence is driven by the need for treatment or the intensity of medical monitoring.

Regarding emergency care, patients with severe asthma were those with the highest prevalence $(47 \%)$ and the highest frequency of hospitalization (13\%). Such findings demonstrate that the lower the severity of the disease, the lower the impact rates of asthma, with residential rescue treatment, reducing the chances of hospitalization, in addition to finding significant differences regarding school absenteeism: children with mild asthma miss school days for shorter periods and children with severe asthma, for longer periods ( $\mathrm{p}=0.043)$. In a cross-sectional study carried out with 715 asthmatics, Roncada et al. ${ }^{24}$ demonstrated that asthma morbidity is high in this population (68\%), with reports of recurrent symptoms of this disease over the last 12 months. Among the 715 students, 56\% attended at least one medical appointment for asthma, and only $24 \%$ underwent specialized medical follow-up, with half of the children using oral corticosteroids in the last 12 months and $8 \%$ being hospitalized for the disease, with a prevalence of school absenteeism of $57 \%$.

In assessing lung function (spirometry), comparing it to asthma severity, the results of the present study demonstrate a difference between basal values for $\mathrm{FEV}_{1}, \mathrm{FVC}$ and FEF25-75\% ( $\mathrm{p}=0.002, \mathrm{p}=0.001$ and $\mathrm{p}=0.036$, respectively) and post-use of bronchodilator for $\mathrm{FEV}_{1}$ and $\mathrm{FVC}(\mathrm{p}=0.008$ and $\mathrm{p}=0.037$, respectively), with worse lung volume/capacity for the group with moderate asthma group, followed by the group with severe asthma, with the best scores belonging to the group with mild asthma. These findings may be related to the treatment of groups and the time of year evaluated, considering that, in the referral center, patients with mild and moderate asthma have drug reduction in the periods of hot season (summer), with the group with severe asthma continuing to have severe symptoms 12 months a year. However, when comparing the difference between pre- and post-bronchodilator, no differences were found with the use of $400 \mu \mathrm{g}$ of salbutamol. A possible answer to these findings is the fact that patients in the group with mild asthma have better lung function, as described in the literature, ${ }^{25}$ and those in the group with severe asthma are prescribed treatment with Omalizumab, ${ }^{26}$ making the group with moderate asthma the one with the worst lung function scores. In addition, a recently published study ${ }^{27}$ demonstrates that the bronchodilator response, correlating with asthma control and assessed by the ACT questionnaire, did not show significant differences before and after the administration of $400 \mu \mathrm{g}$ of salbutamol between the groups.

In assessing atopic hypersensitivity levels using the skin prick test, even though there was an increase in prevalence according to severity, the differences were not significantly relevant (mild asthma $=67 \%$, moderate asthma $=75 \%$, and severe asthma $=86 \% ; p=0.352$ ). Nonetheless, even though no differences were found between the groups, atopic prevalence was relatively high compared to another study in the 
same region, ${ }^{28}$ which showed minimum values of $67 \%$ for the group with mild asthma. Household dust mites were mainly responsible for the high diagnosis, with a positive response in $76 \%$ of cases of severe asthma for Dermatophagoides pteronyssinus and Dermatophagoides farinae, followed by $67 \%$ for cases of mild asthma for Blomia tropicalis. The epitheliums of dogs and cats had the lowest rates of atopic prevalence. Similar findings for the prevalence of atopy are presented in a study conducted in the same region, in which $85 \%$ of children were atopic, with Dermatophagoides farinae, Dermatophagoides pteronyssinus and Blomia tropicalis as their main triggering factors. ${ }^{29}$

One of the main outcome assessments for the management of asthma is that of HRQOL, represented in this study as QOL (generic module) and HRQOL-asthma. Both assessments were found to be very close to normal standards, regardless of asthma severity. One of the possible answers to these findings is that children are being followed up on an outpatient basis, increasing the perception of HRQOL. Moreover, Matsunaga et al..$^{30}$ demonstrated that QOL is directly related to the level of asthma control and severity, because children and adolescents with better control and lesser disease severity had better QOL. Thus, levels of asthma control and severity can influence the QOL of asthmatic patients and their families. These findings underscore the importance of adequate monitoring of this population, with an emphasis on factors that lead to an unfavorable outcome, such as lack of adherence to treatment, contact with triggering factors, inappropriate use of inhalation devices and inaccessibility to medicines and medical services. Perhaps, these last two topics are the reasons for the findings of this study not having demonstrated any differences in QOL scores between the groups with mild, moderate and severe asthma.

The assessment of adherence to treatment based on the report of the person responsible for the patient is one of the study limitations. In some cases, such factor could under or overestimate the data. Hence, the ideal practice would be using a metered-dose inhaler that recorded the date and time of use of the medication, a resource which was not available.

Although the clinical characteristics of children with mild, moderate and severe asthma are similar in the present study, the mechanisms and risk factors should be better studied, as well as their association with the recurrence of symptoms, lifestyle, adherence to treatment, lung function, atopy and QOL levels. In this way, we can increase the levels of asthma control, reducing the global burden of the disease and providing better HRQOL for these children, adolescents and their family members.

\section{Funding}

The study was not financed.

\section{Conflict of interests}

The authors declare there is no conflict of interests.

\section{REFERENCES}

1. Global Initiative for Asthma - GINA [homepage on the Internet]. 2017 GINA Report, Global strategy for asthma management and prevention 2017 [cited 2017 Mar 06]. Available from: http://ginasthma.org/2017-ginareport-global-strategy-for-asthma-management-andprevention/.

2. Bateman ED, Hurd SS, Barnes PJ, Bousquet J, Drazen JM, FitzGerald $M$, et al. Global strategy for asthma management and prevention: GINA executive summary. Eur Respir J. 2008;31:143-78. https://doi. org/10.1183/09031936.00138707

3. Cella DF. Quality of life: concepts and definition. J Pain Symptom Manage. 1994;9:186-92. https://doi. org/10.1183/09031936.00138707

4. Teixeira IP, Novais IP, Pinto RM, Cheik NC. Adaptação cultural e validação do Questionário KINDL no Brasil para adolescentes entre 12 e 16 anos. Rev Bras Epidemiol. 2012;15:845-57. http://dx.doi.org/10.1590/S1415-790X2012000400015

5. La Scala CS, Naspitz CK, Solé D. Adaptation and validation of the Pediatric Asthma Quality of Life Questionnaire
(PAQLQ) in Brazilian asthmatic children and adolescents. J Pediatr (Rio J). 2005;81:54-60. http://dx.doi.org/10.1590/ S0021-75572005000100011

6. Lopes MT, Ferraro AA, Koch VH. Reliability of the Brazilian version of the PedsQL - ESDR questionnaire to evaluate quality of life of children and adolescents. J Bras Nefrol. 2015;37:158-65. http://dx.doi.org/10.5935/01012800.20150026

7. Leite M, Ponte EV, Petroni J, D'Oliveira Junior A, Pizzichini E, Cruz ÁA. Evaluation of the asthma control questionnaire validated for use in Brazil. J Bras Pneumol. 2008;34:756-63. https://doi.org/10.1590/s1806-37132008001000002

8. Horak F, Doberer D, Eber E, Horak E, Pohl W, Riedler J, et al. Diagnosis and management of asthma-Statement on the 2015 GINA Guidelines. Wien Klin Wochenschr. 2016;128:541-54. https://doi.org/10.1007/s00508-0161019-4

9. Vidal PC. Validação dos valores de referência multi-étnicos para espirometria (GLI 2012) em crianças brasileiras [PhD thesis]. Porto Alegre (RS): PUCRS; 2012. 
10. Teixeira IP, Novais IP, Pinto RM, Cheik NC. Cultural adaptation and validation of the KINDL questionnaire in Brazil for adolescents between 12 and 16 years of age. Rev Bras Epidemiol. 2012;15:845-57. https://doi.org/10.1590/s1415$790 \times 2012000400015$

11. Roxo JP, Ponte EV, Ramos DC, Pimentel L, D'Oliveira Junior A, Cruz AA. Portuguese-language version of the Asthma Control Test. J Bras Pneumol. 2010;36:159-66. https://doi. org/10.1590/s1806-37132010000200002

12. Cole TJ, Flegal KM, Nicholls D, Jackson AA. Body mass index cut offs to define thinness in children and adolescents: international survey. BMJ. 2007;335:194. https://doi. org/10.1136/bmj.39238.399444.55

13. Farias Junior JC, Lopes AS, Mota J, Santos MP, Ribeiro JC, Hallal PC. Validity and reproducibility of a physical activity questionnaire for adolescents: adapting the SelfAdministered Physical Activity Checklist. Rev Bras Epidemiol. 2012;15:198-210. https://doi.org/10.1590/s1415-790x2012000100018

14. Chan EY, Dundas I, Bridge PD, Healy MJ, McKenzie SA. Skin-prick testing as a diagnostic aid for childhood asthma. Pediatr Pulmonol. 2005;39:558-62. https://doi.org/10.1002/ ppul.20227

15. Holderness $H$, Chin N, Ossip DJ, Fagnano M, Reznik M, Halterman JS. Physical activity, restrictions in activity, and body mass index among urban children with persistent asthma. Ann Allergy Asthma Immunol. 2017;118:433-8. https://doi.org/10.1016/j.anai.2017.01.014

16. Chen YC, Chih AH, Chen JR, Liou TH, Pan WH, Lee YL. Rapid adiposity growth increases risks of new-onset asthma and airway inflammation in children. Int J Obes (Lond). 2017;41:1035-41. https://doi.org/10.1038/ijo.2017.67

17. Musaiger AO, Al-Mufty BA, Al-Hazzaa HM. Eating habits, inactivity, and sedentary behavior among adolescents in Iraq: sex differences in the hidden risks of noncommunicable diseases. Food Nutr Bull. 2014;35:12-9. https://doi. org/10.1177/156482651403500102

18. Hoare E, Milton K, Foster C, Allender S. The associations between sedentary behaviour and mental health among adolescents: a systematic review. Int J Behav Nutr Phys Act. 2016;13:108. https://doi.org/10.1186/s12966-016-0432-4

19. Stelmach I, Cichalewski Ł, Majak P, Smejda K, Podlecka D, Jerzyńska J, et al. School environmental factors are predictive for exercise-induced symptoms in children. Respir Med. 2016;112:25-30. https://doi.org/10.1016/j. rmed.2016.01.010

20. Lochte L, Nielsen KG, Petersen PE, Platts-Mills TA. Childhood asthma and physical activity: a systematic review with meta-analysis and Graphic Appraisal Tool for Epidemiology assessment. BMC Pediatr. 2016;16:50. https://doi. org/10.1186/s12887-016-0571-4

21. Halwani R, Vazquez-Tello A, Horanieh N, Dulgom S, Al-AseriZ, Al-Khamis N, et al. Risk factors hindering asthma symptoms control in Saudi children and adolescents. Pediatr Int. 2017;59:661-8. https://doi.org/10.1111/ped.13268

22. Saito N, Kamata A, Itoga M, Tamaki M, Kayaba H, Ritz T. Assessment of biological, psychological and adherence factors in the prediction of step-down treatment for patients with well-controlled asthma. Clin Exp Allergy. 2017;47:467-78. https://doi.org/10.1111/cea.12888

23. Engelkes M, Janssens HM, Jongste JC, Sturkenboom MC Verhamme KM. Prescription patterns, adherence and characteristics of non-adherence in children with asthma in primary care. Pediatr Allergy Immunol. 2016;27:201-8. https://doi.org/10.1111/pai.12507

24. Roncada C, Oliveira SG, Cidade SF, Sarria EE, Mattiello R, Ojeda BS, et al. Burden of asthma among inner-city children from Southern Brazil. J Asthma. 2016;53:498-504. https:// doi.org/10.3109/02770903.2015.1108438

25. Bacharier LB, Strunk RC, Mauger D, White D, Lemanske Junior RF, Sorkness CA. Classifying asthma severity in children: mismatch between symptoms, medication use, and lung function. Am J Respir Crit Care Med. 2004;170:426-32. https://doi.org/10.1164/rccm.200308-11780C

26. Cusack RP, Sahadevan A, Lane SJ. Qualitative effects of omalizumab on concomitant IgE-mediated disease in a severe asthmatic population: a real life observational study. QJM. 2016;109:601-4. https://doi.org/10.1093/qjmed/hcw027

27. Heffler E, Crimi C, Campisi R, Sichili S, Nicolosi G, Porto M, et al. Bronchodilator response as a marker of poor asthma control. Resp Med. 2016;112:45-50. https://doi.org/10.1016/j. rmed.2016.01.012

28. Fiore RW, Comparsi $A B$, Reck CL, Oliveira J, Pampanelli $\mathrm{KB}$, Fritscher CC. Asthma and atopy prevalence in a group of students from Porto Alegre, Rio Grande do Sul. J Pneumol. 2001;27:237-42. https://doi.org/10.1590/S010235862001000500002

29. Rodrigues AM, Roncada C, Santos G, Heinzmann-Filho JP, de Souza RG, Vargas MH, et al. Clinical characteristics of children and adolescents with severe therapy-resistant asthma in Brazil. J Bras Pneumol. 2015;41:343-50. http:// dx.doi.org/10.1590/S1806-37132015000004462

30. Matsunaga NY, Ribeiro MA, Saad IA, Morcillo AM, Ribeiro JD, Toro AA. Evaluation of quality of life according to asthma control and asthma severity in children and adolescents. J Bras Pneumol. 2015;41:502-8. https://doi.org/10.1590/ S1806-37562015000000186 